\title{
A novel bifunctional GH51 exo- $\alpha$-L-arabinofuranosidase/endo-xylanase from Alicyclobacillus sp. A4 with significant biomass-degrading capacity
}

Wenxia Yang ${ }^{\dagger}$, Yingguo Bai ${ }^{\dagger}$, Peilong Yang, Huiying Luo, Huoqing Huang, Kun Meng, Pengjun Shi ${ }^{*}$, Yaru Wang and Bin Yao ${ }^{*}$

\begin{abstract}
Background: Improving the hydrolytic performance of xylanolytic enzymes on arabinoxylan is of importance in the ethanol fermentation industry. Supplementation of debranching (arabinofuranosidase) and depolymerizing (xylanase) enzymes is a way to address the problem. In the present study, we identified a bifunctional a-L-arabinofuranosidase/ endo-xylanase (Ac-Abf51A) of glycoside hydrolase family 51 in Alicyclobacillus sp. strain A4. Its biochemical stability and great hydrolysis efficiency against complex biomass make it a potential candidate for the production of biofuels.

Results: The gene encoding Ac-Abf51 A was cloned. The comparison of its sequence with reference proteins having resolved 3D-structures revealed nine key residues involved in catalysis and substrate-binding interaction. Recombinant Ac-Abf51A produced in Escherichia coli showed optimal activity at pH 6.0 and $60^{\circ} \mathrm{C}$ with 4-nitrophenyl-aL-arabinofuranoside as the substrate. The enzyme exhibited an exo-type mode of action on polyarabinosides by catalyzing the cleavage of a-1,2- and a-1,3-linked arabinofuranose side chains in sugar beet arabinan and water-soluble wheat arabinoxylan and a-1,5-linked arabinofuranosidic bonds in debranched sugar beet arabinan. Surprisingly, it had capacity to release xylobiose and xylotriose from wheat arabinoxylan and was active on xylooligosaccharides (xylohexaose 1.2/mM/min, xylopentaose $6.9 / \mathrm{mM} / \mathrm{min}$, and xylotetraose $19.7 / \mathrm{mM} / \mathrm{min}$ ), however a lower level of activity. Moreover, Ac-Abf51A showed greater synergistic effect in combination with xylanase (2.92-fold) on wheat arabinoxylan degradation than other reported enzymes, for the amounts of arabinose, xylose, and xylobiose were all increased in comparison to that by the enzymes acting individually.

Conclusions: This study for the first time reports a GH51 enzyme with both exo-a-L-arabinofuranosidase and endoxylanase activities. It was stable over a broad pH range and at high temperature, and showed greater synergistic effect with xylanase on the degradation of wheat arabinoxylan than other counterparts. The distinguished synergy might be ascribed to its bifunctional a-L-arabinofuranosidase/xylanase activity, which may represent a possible way to degrade biomass at lower enzyme loadings.
\end{abstract}

Keywords: Alicyclobacillus sp. A4, a-L-Arabinofuranosidase (Abf), Xylanase, Glycosyl hydrolase (GH), Synergism

\footnotetext{
*Correspondence: shipengjun@caas.cn; binyao@caas.cn

tWenxia Yang and Yingguo Bai contributed equally to this paper

Key Laboratory for Feed Biotechnology of the Ministry of Agriculture,

Feed Research Institute, Chinese Academy of Agricultural Sciences, No. 12

Zhongguancun South Street, Beijing 100081, People's Republic of China
} 


\section{Background}

Hemicellulose, the second most abundant polysaccharide in plants, combines with cellulose and lignin to compose lignocellulose of plant cell walls, and accounts for about 20-35\% of lignocellulosic biomass [1, 2]. It mainly consists of xylan, glucuronoxylan, arabinoxylan, glucomannan, and xyloglucan, and has attracted much attention for their industrial importance in bioconversion of plant biomass to biofuel, improvement of animal feedstock digestibility, and organic synthesis [3, 4]. Heterogeneous xylans are the major constituents of hemicellulose. Among them, arabinoxylans such as those found in wheat straw [5] consist of a backbone of $\beta$-1,4-linked $\mathrm{D}$-xylopyranose residues that are extensively decorated at $\mathrm{C}-2$ and/or $\mathrm{C}-3$ positions with arabinofuranose side chains [6, 7]. Arabinan, a component of pectin, contains a backbone of $\alpha$-1,5-linked L-arabinofuranosyl residues as well as $\alpha-1,2$ - and $\alpha-1,3$-linked side chains [8]. Thus, due to the structural complexity of xylans, efficient hydrolysis of wheat arabinoxylan to achieve high xylose yields by complete xylan monomerization requires supplementing xylanases with $\alpha$-L-arabinofuranosidases and other accessory enzymes [9].

Exo-acting $\alpha$-L-arabinofuranosidases (Abfs, EC 3.2.1.55) catalyze the hydrolysis of terminal non-reducing $\alpha-1,2-, \alpha-1,3-$, and $\alpha-1,5-\mathrm{L}$-arabinofuranosyl residues [10]. In recent years, Abfs have received much attention because of their potential applications in the processing of fruits and cereals for aroma improvement and the conversion of hemicellulose to fuels and chemicals $[8,11-$ 13]. Based on amino acid sequence, primary structure similarity, and hydrophobic cluster analysis, Abfs have been classified into glycosyl hydrolase (GH) families 3, 43, 51, 54, and 62 [14, 15]. Members of different families display specific preference for substrates. For example, those of GH43 hydrolyze $\alpha$-1,5-linked arabinofurano-oligosaccharides, GH62 Abfs show absolute specificity for arabinoxylan, and members of GH51 and GH54 catalyze the removal of both $\alpha-1,2$ and $\alpha-1,3$-linked arabinofuranose side chains from arabinan and xylan [16].

Until now, bacterial GH51 Abfs from Anoxybacillus kestanbolensis [17], Clostridium stercorarium [18], Geobacillus stearothermophilus [19], Bacillus pumilus [20], Bifidobacterium longum [21], and Streptomyces spp. [22-24] have been characterized, and the structures of six bacterial Abfs have been resolved, which all perform hydrolysis via a retaining mechanism [25]. Previous studies indicate that GH51 Abfs have various modes of action on different substrates. This broad specificity against distinct branching modifications represents a great advantage for biotechnological processing of complex and branched polysaccharides [26]. In this study, we report the characterization of a novel Alicyclobacillus sp. A4 GH51 $\alpha$-L-arabinofuranosidase (Ac-Abf51A) with both exo- $\alpha-\mathrm{L}$-arabinofuranosidase and endo-xylanase activities, which is significantly different from previously reported GH51 arabinofuranosidases in substrate specificity and would play an important role in biomass hydrolysis.

\section{Results}

\section{Gene cloning and sequence analysis}

The full-length Abf gene, Ac-abf51A (GenBank accession no.KT781102), contains $1509 \mathrm{bp}$ and encodes a 502-residue polypeptide with a calculated molecular mass of $56.7 \mathrm{kDa}$. The deduced amino acid sequence of Ac-Abf51A is most similar to a putative Abf of Alicyclobacillus hesperidum (99 \% identity; WP_006446014.1), and $68 \%$ identical with the crystal structure-resolved Abf from G. stearothermophilus T6 (1PZ3). Using the Accelrys Discovery Studio software with $1 \mathrm{PZ} 3$ as the template, modeled Ac-Abf51A folds into two modules: the N-terminal catalytic module of the frequently encountered $(\alpha / \beta)_{8}$ barrel (TIM barrel) of GH51 and the C-terminal module of 12 -stranded $\beta$-sandwich with a jelly-roll topology (Additional file 1$)$. The structure of the $(\alpha / \beta)_{8}$ barrel domain places Ac-Abf51A into the superfamily of clan GH-A, in which two conserved glutamates (Glu175 and Glu294) were found on strands $\beta-4$ (acid/base) and $\beta-7$ (nucleophile), respectively (Fig. 1). Based on homology analysis of amino acid sequences with the characterized GH51 Abf with crystal structure [17], nine key residues including Glu29, Arg69, Asn74, Asn174, Glu175, His244, Tyr246, Glu294, and Gln351 are conserved and probably involved in catalysis and substrate-binding interaction (Fig. 1).

\section{Expression and purification of recombinant Ac-Abf51A}

After induction with IPTG at $30^{\circ} \mathrm{C}$ for $6 \mathrm{~h}$, the whole $E$. coli cell lysates showed an Abf activity of $2.6 \mathrm{U} / \mathrm{mL}$. The recombinant Ac-Abf51A was purified by one-step immobilized metal-affinity chromatography (IMAC). The specific activity of purified Ac-Abf51A was $18.2 \mathrm{U} / \mathrm{mg}$ with

(See figure on next page.)

Fig. 1 Amino acid sequence alignment of Ac-Abf51A from Alicyclobacillus sp. A4 with CelA4 from Alicyclobacillus sp. A4 (ADI82825.1) and other GH51 Abfs from Bifidobacterium longum B667 (PDB: 2Y2 W), Geobacillus stearothermophilus T6 (PDB: 1PZ3), Clostridium thermocellum ATCC 27405 (PDB: 2C7F), Thermobacillus xylanilyticus D3 (PDB: 2VRK), Thermotoga maritima MSB8 (PDB: 3UG3), and Thermotoga petrophila RKU-1 (PDB: 3S2C), using the ClustalW program. Identical and similar amino acids are indicated by black and gray shades, respectively. The catalytic glutamate residues are indicated by asterisk, and the conserved residues are indicated by hash 


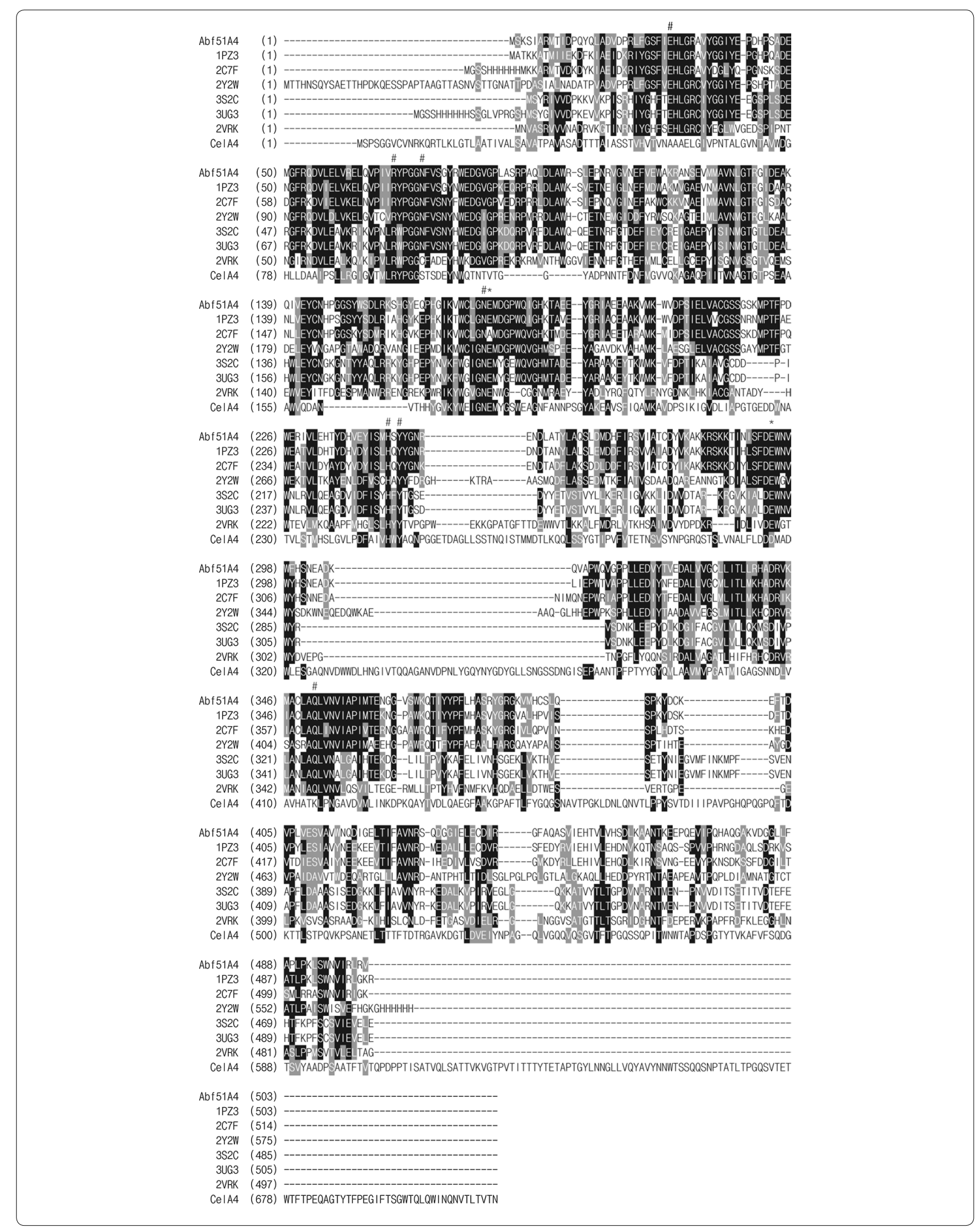


4-nitrophenyl- $\alpha$-L-arabinofuranoside as the substrate. The purified enzyme migrated as a single band with an apparent molecular mass of $57.0 \mathrm{kDa}$, as determined by SDS-PAGE analysis (Fig. 2).

\section{Biochemical characterization}

With 4-nitrophenyl- $\alpha$-L-arabinofuranoside as the substrate, Ac-Abf51A exhibited the highest Abf activity at pH 6.0 (Fig. 3a). The enzyme retained more than $80 \%$ of the initial activity after incubation at $\mathrm{pH} 4.0-11.0,37^{\circ} \mathrm{C}$ for $1 \mathrm{~h}$ (Fig. 3b). When assayed at pH 6.0, Ac-Abf51A was most active at $60{ }^{\circ} \mathrm{C}$ (Fig. 3c). The enzyme retained full activity after 12 -h incubation at $60{ }^{\circ} \mathrm{C}$ and $65{ }^{\circ} \mathrm{C}$, more than $80 \%$ of the initial activity at $70{ }^{\circ} \mathrm{C}$ for $1 \mathrm{~h}$, and more than $30 \%$ of the activity at $80^{\circ} \mathrm{C}$ for $30 \mathrm{~min}$ (Fig. $3 \mathrm{~d}$ ).

Most metal ions and chemicals had little or no effect on Ac-Abf51A (Table 1). However, the presence of $\mathrm{K}^{+}, \mathrm{Co}^{2+}$, $\mathrm{Ag}^{+}$, and SDS strongly inhibited the enzymatic activity of Ac-Abf51A.

\section{Substrate specificity and kinetic parameters}

Ac-Abf51A had broad substrate specificity. The capacity of purified Ac-Abf51A to hydrolyze a range of different substrates was evaluated. For 4-nitrophenyl-glycosides and polysaccharides with reaction time within $10 \mathrm{~min}$, it acted solely on 4-nitrophenyl- $\alpha$-L-arabinofuranoside. When the incubation period was lengthened to $5 \mathrm{~h}$,

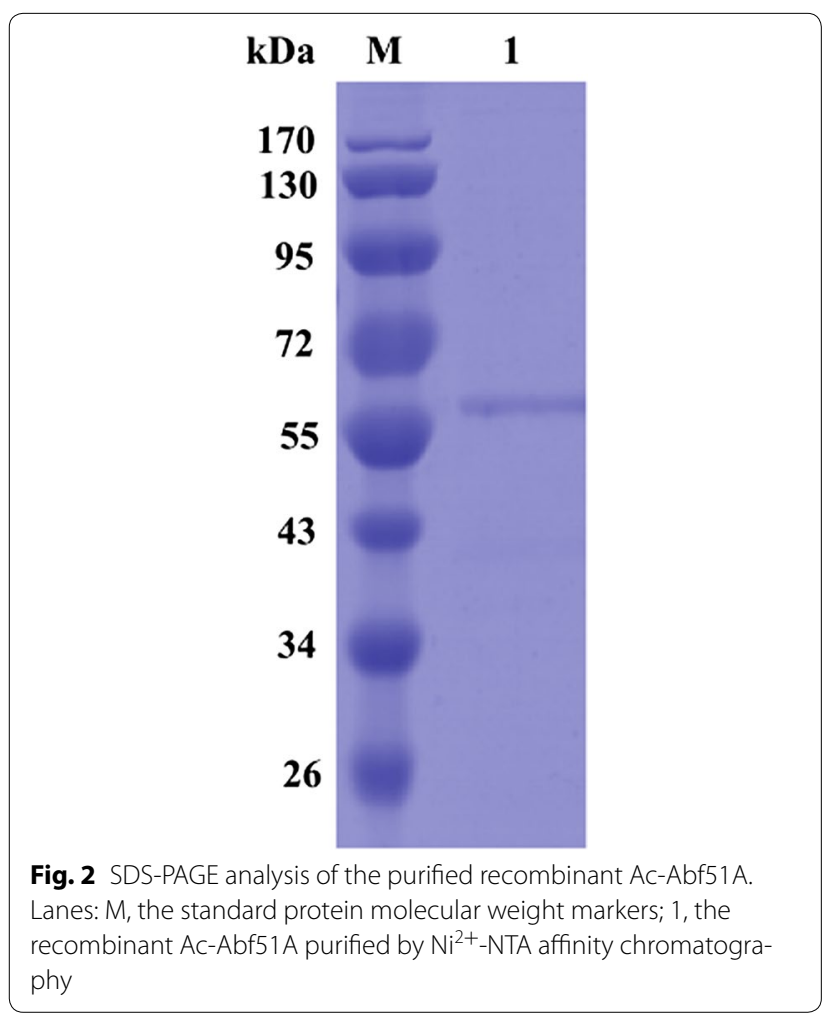

Ac-Abf51A showed weak activity against 4-nitrophenyl$\beta$-D-xylopyranoside $(0.026 \%$ activity relative to that on 4-nitrophenyl- $\alpha$-L-arabinofuranoside). The $K_{\mathrm{m}}, V_{\max }$, and $k_{\text {cat }}$ values of Ac-Abf51A towards 4-nitrophenyl- $\alpha$ $\mathrm{L}$-arabinofuranoside were determined to be $0.46 \mathrm{mM}$, $24.4 \mu \mathrm{mol} / \mathrm{min} / \mathrm{mg}$, and $23.0 / \mathrm{s}$, respectively. The $k_{\text {cat }} / K_{\mathrm{m}}$ value was $50 / \mathrm{mM} / \mathrm{s}$.

For longer incubation (up to $12 \mathrm{~h}$ ), it was active on sugar beet arabinan and debranched sugar beet arabinan, releasing arabinose as the final product $(0.57$ and $0.30 \mathrm{mg} / \mathrm{mL}$, respectively) (Additional file 2). It also released arabinose, xylobiose, xylotriose, and xylotetraose from water-soluble wheat arabinoxylan.

Further time course analysis of the water-soluble wheat arabinoxylan digestion by Ac-Abf51A indicated that arabinose was yielded as the sole product at the beginning, and xylobiose, xylotriose, and xylotetraose were also released after a prolonged incubation (Fig. 4). When using xylooligosaccharides as the substrates, Ac-Abf51A exhibited an endo-mode of action on xylohexaose, xylopentaose and xylotetraose, releasing products of lower degree of polymerization. However, it showed barely detectable activity on xylotriose and xylobiose. The $k_{\text {cat }} / K_{\mathrm{m}}$ values of Ac-Abf51A on xylotetraose, xylopentaose, and xylohexaose were $1.2 / \mathrm{mM} / \mathrm{min}, 6.9 / \mathrm{mM} / \mathrm{min}$, and $19.7 / \mathrm{mM} / \mathrm{min}$, respectively (Additional file 3 ).

\section{Characterization of four mutants of Ac-Abf51A}

Four Ac-Abf51A mutants containing the $(\alpha / \beta)_{8}$ barrel module alone (Ac-Abf51An), the jelly-roll module alone (Ac-Abf51Ac), and the two catalytic glutamic acid residues substituted by glutamine (E175Q and E194Q), respectively, were successfully expressed in E. coli BL21 (DE3) and purified to homogeneity by Ni-NTA columns individually. Except for Ac-Abf51An that has both exo$\alpha-\mathrm{L}$-arabinofuranosidase and endo-xylanase activities, other three mutant proteins were completely inactive towards 4-nitrophenyl- $\alpha$-L-arabinofuranoside, water-soluble wheat arabinoxylan, and xylotetraose, xylopentaose, and xylohexaose. The results showed that Ac-Abf51A catalyzes the two types of substrate at the same active sites within a single catalytic domain.

\section{Synergetic effects}

The product composition of water-soluble wheat arabinoxylan hydrolysis by Ac-Abf51A and endo-xylanase XynBE18 individually or in combination were determined by HPAEC-PAD. XynBE18 released only xylose and xylobiose, and Ac-Abf51A liberated arabinose and trace amounts of xylobiose and xylotriose. In comparison with the hydrolysis products by XynBE18 or Ac-Abf51A alone, all enzyme combinations had significant synergistic effects on wheat arabinoxylan degradation, producing 

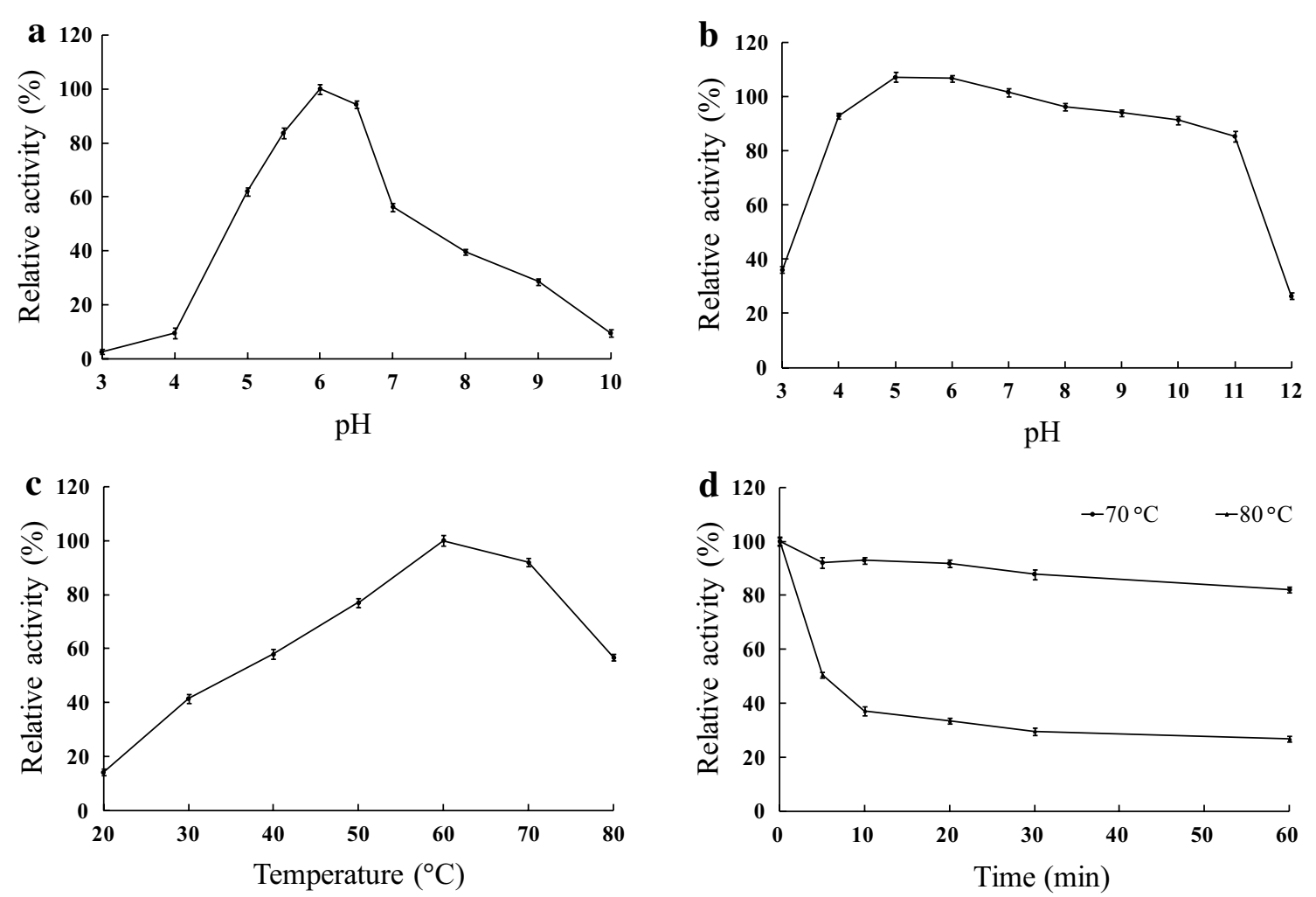

Fig. 3 Characterization of the purified recombinant Ac-Abf51A with 4-nitrophenyl-a-L-arabinofuranoside as the substrate. $\mathbf{a}$ The effect of pH on enzyme activity. The activity assays were performed at $60^{\circ} \mathrm{C}$ in buffers of $\mathrm{pH} 3.0-10.0$ for $10 \mathrm{~min}$. b pH stability of Ac-Abf51 A. After pre-incubating the enzyme at $37^{\circ} \mathrm{C}$ for $1 \mathrm{~h}$ at pH 3.0-12.0, the residual activities were measured in $100 \mathrm{mM}$ Mcllvaine buffer (pH $6.0,60^{\circ} \mathrm{C}$ and $\left.10 \mathrm{~min}\right)$. c The effect of temperature on enzyme activity measured in $100 \mathrm{mM}$ Mcllvaine buffer ( $\mathrm{pH}$ 6.0) for $10 \mathrm{~min}$. $\mathbf{d}$ Thermostability of purified Ac-Abf51A. The enzyme was pre-incubated at $70^{\circ} \mathrm{C}$ or $80^{\circ} \mathrm{C}$ in $100 \mathrm{mM} \mathrm{Mcllvaine} \mathrm{buffer} \mathrm{(pH} \mathrm{6.0)} \mathrm{for} \mathrm{various} \mathrm{periods,} \mathrm{followed} \mathrm{by} \mathrm{activity} \mathrm{assay} \mathrm{at} \mathrm{pH} 6.0$ and $60{ }^{\circ} \mathrm{C}$ for $10 \mathrm{~min}$

substantially more arabinose, xylobiose, and xylose. The greatest synergy showed no difference, when simultaneous incubation of wheat arabinoxylan with Ac-Abf51A and XynBE18 (2.92-fold increase, Table 2). First addition of Ac-Abf51A followed by XynBE18 had no difference with XynBE18 alone on the production of arabinose and xylose. However, the amount of xylobiose was increased by 1.4-fold (1.26-fold increase in total, Table 2). When XynBE18 was added followed by Ac-Abf51A, more arabinose, xylobiose, and xylotriose were released (2.12-fold increase, Table 2).

\section{Discussion}

To our knowledge, this is the first report on the gene cloning, expression, and characterization of a GH51 $\alpha-\mathrm{L}-$ arabinofuranosidase (Ac-Abf51A) from the genus Alicyclobacillus. This genus contains unusual $\omega$-alicyclic fatty acids in the cell membrane and is thus highly thermoacidophilic [27]. It produces a spectrum of GHs, including GH9 and GH51 cellulases [28-30], GH10 xylanase
[31], GH52 xylosidase [32], and GH113 mannanase [33]. Analysis of the sequence alignment and structure modeling indicated that Ac-Abf51A consists of two modules: the catalytic module of the frequently encountered $(\beta / \alpha)_{8}$ barrel fold and a $C$-terminal jelly-roll module. The overall structure of Ac-Abf51A is very similar to that of the six previously published Abfs from bacteria. Furthermore, among the nine conserved residues within the GH51 arabinofuranosidases, the catalytic acid/base Glu175 is involved in the formation of a hydrogen bond with the conserved His244, and the Arg69 residue appears to keep the catalytic nucleophile Glu294 deprotonated [34]. All these data strongly support the conclusion that AcAbf51A is a putative GH51 Abf.

SignalP 4.1 analysis indicated the absence of putative Sec-type signal peptide in Ac-Abf51A. Prediction of the subcellular location using pSORTb (http://www.psort. org/) indicated that Ac-Abf51A is similar to AbfATK4 from Geobacillus caldoxyloslyticus TK4 [35] and AF from Bacillus stearothermophilus T-6 [36], showing a high 
Table 1 Effect of metal ions and chemical reagents ( $5 \mathrm{mM}$ ) on the activity of purified recombinant Ac-Abf51A

\begin{tabular}{lc}
\hline Chemicals & Relative activity (\%) \\
\hline None & $100.0 \pm 1.5$ \\
$\mathrm{Mg}^{2+}$ & $110.0 \pm 1.8$ \\
$\mathrm{Zn}^{2+}$ & $108.5 \pm 1.7$ \\
$\mathrm{Na}^{+}$ & $108.5 \pm 1.7$ \\
$\mathrm{Li}^{+}$ & $103.0 \pm 1.6$ \\
$\mathrm{Cr}^{3+}$ & $101.9 \pm 1.4$ \\
$\mathrm{Fe}^{3+}$ & $100.7 \pm 2.0$ \\
$\mathrm{Cu}^{2+}$ & $99.2 \pm 0.7$ \\
$\mathrm{Mn}^{2+}$ & $98.0 \pm 1.0$ \\
$\mathrm{Ni}^{2+}$ & $96.3 \pm 1.2$ \\
$\mathrm{~Pb}^{2+}$ & $86.7 \pm 1.5$ \\
$\mathrm{Ca}^{2+}$ & $81.7 \pm 2.6$ \\
$\mathrm{~K}^{+}$ & $58.1 \pm 1.1$ \\
$\mathrm{Co}^{2+}$ & $25.4 \pm 0.5$ \\
$\mathrm{Ag}^{+}$ & $9.6 \pm 1.3$ \\
$\beta-M e r c a p t o e t h a n o l$ & $93.2 \pm 2.4$ \\
$\mathrm{EDTA}$ & $92.1 \pm 2.1$ \\
$\mathrm{SDS}$ & $47.5 \pm 0.6$ \\
\hline
\end{tabular}

a Values represent the mean $\pm \mathrm{SD}(n=3)$ relative to the untreated control samples

probability in the cytoplasmic and extracellular space with the localization scores of 5.86 and 3.83, respectively. In contrast to most bacterial GH51 Abfs that are optimally active under neutral and mesophilic conditions [20-22], Ac-Abf51A was most active at $\mathrm{pH} 6.0$ and $60{ }^{\circ} \mathrm{C}$, and remained stable between $\mathrm{pH} 4.0$ and $11.0,65{ }^{\circ} \mathrm{C}$ for $12 \mathrm{~h}$. However, compared to all characterized Abfs of GH 51, Ac-Abf51A showed distinct and broader substrate specificity [23, 24, 26]. Not surprisingly, the enzyme was most active on the artificial substrate 4-nitrophenyl$\alpha$-L-arabinofuranoside. Unlike GH3 and GH43 Abfs having both $\mathrm{Abf} / \beta$-D-xylosidase activities, most GH51 Abfs have no ability to hydrolyze 4-nitrophenyl- $\beta$-Dxylopyranoside. However, Ac-Abf51A in this study, ArfB from C. stercorarium [18], and AF from B. stearothermophilus T-6 [36] have high Abf activity with weak $\beta$-xylosidase activity, which are less than $1 \%$ relative to the Abf activities. The inactivity of Ac-Abf51A to gum arabic also indicates its specificity towards the furanosidic conformation and $\alpha$-linkages. Ac-Afb51A did not display activity against red debranched arabinan, which is a substrate specific for the endo-1,5-arabinanase activity, indicating its inability to cleave the internal $\alpha-1,5$-linkage. On the other hand, Ac-Afb51A yielded arabinose as the sole hydrolysis product from branched and debranched sugar beet arabinan. These results showed Ac-Afb51A was an exo-acting enzyme that had hydrolytic activity against $\alpha-1,2-, \alpha-1,3-$, or $\alpha-1,5$-linked non-reducing terminal L-arabinofuranose residues [37, 38]. Moreover, it exhibited higher activity against branched (1.9-fold) than debranched sugar beet arabinan, suggesting it preference for the $\alpha$-1,2- and $\alpha-1,3$ - rather than $\alpha-1,5$-glycosidic bonds.

Surprisingly, Ac-Abf51A exhibited activity against water-soluble wheat arabinoxylan, releasing arabinose, xylobiose, xylotriose, and xylotetraose after a prolonged

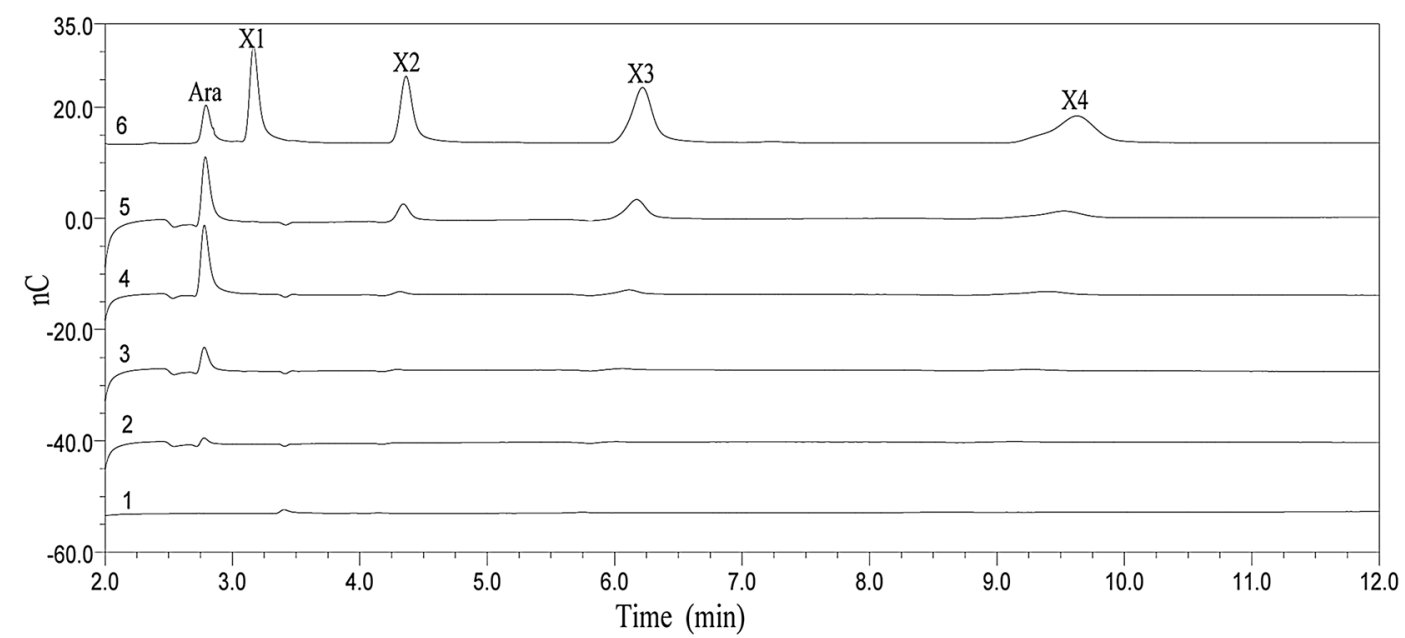

Fig. 4 Time course of hydrolysis of soluble wheat arabinoxylan by Ac-Abf51A. 1, the control of substrate incubated without enzyme for 24 h; 2-5, the hydrolysate with enzyme treatment for $1 \mathrm{~h}, 6 \mathrm{~h}, 12 \mathrm{~h}$, and $24 \mathrm{~h}$, respectively; 6 , the xylooligosaccharide standards: Ara arabinose, X1 xylose, X2 xylobiose, $X 3$ xylotriose, $X 4$ xylotetraose 
Table 2 Simultaneous and sequential reactions of Ac-Abf51A and XynBE18 against water-soluble wheat arabinoxylan

\begin{tabular}{|c|c|c|c|c|c|c|}
\hline \multicolumn{2}{|l|}{ Enzyme added } & \multicolumn{3}{|c|}{ Amounts of xylooligosaccharides (mg/mL) } & \multirow{2}{*}{$\begin{array}{l}\text { Amounts of arabinose } \\
(\mathrm{mg} / \mathrm{mL})\end{array}$} & \multirow{2}{*}{$\begin{array}{l}\text { Degree } \\
\text { of syner- } \\
\mathbf{g y}^{\mathbf{a}}\end{array}$} \\
\hline First reaction & Second reaction & Xylose & Xylobiose & Xylotriose & & \\
\hline XynBE18 & None & $0.26 \pm 0.01$ & $0.45 \pm 0.02$ & - & - & - \\
\hline Ac-Abf51A & None & - & $0.004 \pm 0.00$ & $0.006 \pm 0.00$ & $0.14 \pm 0.01$ & - \\
\hline Ac-Abf51A & XynBE18 & $0.30 \pm 0.01$ & $0.63 \pm 0.03$ & - & $0.14 \pm 0.01$ & 1.26 \\
\hline XynBE18 & Ac-Abf51A & $0.21 \pm 0.01$ & $0.61 \pm 0.02$ & $0.20 \pm 0.01$ & $0.77 \pm 0.03$ & 2.12 \\
\hline XynBE18 + Ac-Abf51A & None & $0.62 \pm 0.03$ & $1.14 \pm 0.04$ & - & $0.72 \pm 0.04$ & 2.92 \\
\hline
\end{tabular}

The amounts of xylooligosaccharides and arabinose were determined by HPAEC

- , not detected

a Degree of synergy is defined as the ratio of the amounts of saccharide released from simultaneous or sequential enzyme combinations to the sum of that released by the individual enzymes

incubation. It has been reported that the GH51 Abf from G. stearothermophilus T-6 [19] can accommodate xylopyranosidic substrate in the active site. However, whether it has endo-xylanase activity was not determined. The time course analysis of wheat arabinoxylan hydrolysis revealed that Ac-Abf51A preferentially removes $\alpha-1,2-$ and $\alpha$-1,3-linked arabinofuranose side chains from arabinoxylan, and hydrolyzes internal $\beta$-1,4-linkages at a much lower rate. Furthermore, Ac-Abf51A also had ability to hydrolyze xylohexaose, xylopentaose, and xylotetraose, but not xylotriose and xylobiose, to shorter xylooligosaccharides. The catalytic efficiency of Ac-Abf51A improved slightly with increasing polymerization degree of xylooligosaccharides up to six (the catalytic efficiency ratio of xylotetraose, xylopentaose, and xylohexaose was 1:5.8:16.4). These results suggested that Ac-Abf51A exhibits an endo-mode of action against xylan. The replacement of Glu175 or Glu294 with Gln resulted in a complete loss of both $\alpha$-L-arabinofuranosidase and endo-xylanase activities, indicating that Ac-Abf51A catalyzes the hydrolysis of these substrates at the same active center. Thus, this is the first report on a novel GH51 Abf having endo-xylanase activity.

Synergy of hydrolytic enzymes has been extensively studied in prior studies [39-41], which is a useful way to improve sugar yield at low cost. When Ac-Abf51A was incubated in combination with endo-xylanase XynBE18 sequentially or simultaneously to degrade wheat arabinoxylan, more reducing sugars were released. There was no significant synergy increase in sequential reaction of Ac-Abf51A followed by XynBE18. But when Ac-Abf51A was added after XynBE18, the amounts of arabinose, xylobiose, and xylotriose released were higher than that by the two enzymes acting separately. The results suggest that efficient degradation of wheat arabinoxylan is achieved by the first cleavage of the main chains with XynBE18 followed by branch removal with Ac-Abf51A. Moreover, the synergy degree of the simultaneous reactions was higher than that of the sequential reactions. As results, Ac-Abf51A plays a role in the release of both arabinose and xylose moieties from arabinose-containing xylooligosaccharides generated by xylanase [42] Discovery of this bifunctional Abf/xylanase is seminal to the structural analysis of the catalytic mechanisms of GH51 Abfs. Considering the distinct substrate specificity and biochemical stability, Ac-Abf51A has great application potentials for biomass degradation and refining.

\section{Conclusions}

Thermoacidophilic Alicyclobacillus sp. A4 is an excellent producer of CAZymes, especially of hemicellulases and cellulases. This study firstly reported the gene cloning, expression and characterization of an auxiliary $\alpha$-L-arabinofuranosidase of GH51. Neutral Ac-Abf51A remained stable over a broad $\mathrm{pH}$ range $(\mathrm{pH} 4.0-11.0)$ and high temperature $\left(70{ }^{\circ} \mathrm{C}\right)$, and exhibited an exo-type mode of action towards polyarabinosides. It had ability to release arabinose, xylobiose, and xylotriose from wheat arabinoxylan, and exhibited endo-type action towards xylooligosaccharides with a lower level of activity. This is the first report of a GH51 Abf that has endo-xylanase activity. The broad substrate specificity, biochemical stability, and great synergistic effect with xylanase make AcAbf51A a potentially interesting enzyme for application in industrial biomass degradation.

\section{Methods}

\section{Strains and culture medium}

Alicyclobacillus sp. A4 CGMCC 3147 (whole genome sequenced, unpublished) was maintained in our laboratory [31]. Escherichia coli strains Trans I-T1 and BL21 (DE3) (TransGen) were maintained in Luria-Bertani (LB) broth or on agar plates at $37^{\circ} \mathrm{C}$ for gene cloning and expression, respectively. Substrates were purchased from Sigma or Megazyme. All other chemicals were of analytical grade and commercially available. 


\section{Gene cloning and sequence analysis}

The gene fragment of $A c$-abf51A (no signal peptide coding sequence based on SignalP 4.0 prediction) was amplified from the genome of strain A4 by PCR using the expression primers (abf51F: 5'-CGCCATATGTCCAAGTCGATTGCACGTATG-3' and abf51R: 5'-GACGCGGCCGCCACGCGCAATCGAATGACG-3', NdeI and NotI sites underlined, respectively). The PCR products were gel-purified with Agarose Gel DNA Purification kit (TaKaRa), ligated into a pGEMT easy vector (Promega), and transformed into E. coli Trans I-T1 for sequencing. The nucleotide sequence was assembled and analyzed using Vector NTI Advance 11.5 software (Invitrogen). BlastN and BlastP programs (http://www.ncbi.nlm.nih. gov/BLAST/) were used to analyze the nucleotide and deduced amino acid sequences, respectively.

\section{Protein expression and purification}

$A c-a b f 51 A$ was obtained by digesting the recombinant plasmid pGEMT-Ac-abf51A with restriction endonucleases NdeI and NotI (TaKaRa), and was cloned into the $N d e \mathrm{I}$ and NotI sites of pET-30a(+) vector (Novagen). The recombinant plasmid pET-Ac-abf51A was then transformed into the $E$. coli BL21 (DE3) competent cells. The positive transformants harboring pET-Ac-abf51A were identified by PCR amplification, and further cultured in LB medium supplemented with $100 \mu \mathrm{g} / \mathrm{mL}$ kanamycin at $37{ }^{\circ} \mathrm{C}$ to an $\mathrm{A}_{600}$ of approximately 0.6. Gene expression was induced at $30{ }^{\circ} \mathrm{C}$ for $6 \mathrm{~h}$ by isopropyl- $\beta$-D-1thiogalactopyranoside (IPTG) with a final concentration of $0.6 \mathrm{mM}$. The induced cultures were centrifuged at $12,000 \times g$ for $5 \mathrm{~min}$ at $4{ }^{\circ} \mathrm{C}$ to harvest cells. The pellet $(5 \mathrm{~g})$ re-suspended in $25 \mathrm{ml}$ of lysis buffer $(20 \mathrm{mM}$ Tris-HCl, $0.5 \mathrm{M} \mathrm{NaCl}, \mathrm{pH}$ 7.6) was sonicated with an Ultrasonic Cell Disruptor (Scientz) on ice with 100 short bursts at $150 \mathrm{~W}$ of $6 \mathrm{~s}$ followed by intervals of $15 \mathrm{~s}$ for cooling. After removal of cell debris by centrifugation, the supernatant was subjected to $\mathrm{Ni}^{2+}$-NTA chromatography with a linear $20-300 \mathrm{mM}$ imidazole gradient in $50 \mathrm{mM}$ Tris- $\mathrm{HCl}, 500 \mathrm{mM} \mathrm{NaCl}, \mathrm{pH}$ 7.6. The fractions exhibiting enzyme activities were pooled, concentrated, and assayed by sodium dodecyl sulfate-polyacrylamide gel electrophoresis (SDS-PAGE). The Bradford protein assay was employed to determine protein concentration at $595 \mathrm{~nm}$ with bovine serum albumin as the standard.

\section{Enzyme assay}

Abf activity was assayed as described previously [21]. The standard reaction system consisted of $250 \mu \mathrm{L}$ of appropriately diluted enzyme and $250 \mu \mathrm{L}$ of McIlvaine buffer ( $\mathrm{pH}$ 6.0) containing $2 \mathrm{mM}$ 4-nitrophenyl- $\alpha-\mathrm{L}$ arabinofuranoside. After incubation at $60{ }^{\circ} \mathrm{C}$ for $10 \mathrm{~min}$, $1.5 \mathrm{~mL}$ of $1.0 \mathrm{M} \mathrm{Na}_{2} \mathrm{CO}_{3}$ was added into the system to terminate the reaction. The amount of $p$-nitrophenol released was determined spectrophotometrically by reading the absorbance at $405 \mathrm{~nm}$. One unit of Abf activity was defined as the amount of enzyme that released $1 \mu \mathrm{mol}$ of 4-nitrophenol per min under the assay conditions.

The dinitrosalicylic acid (DNSA) method [43] was used to assay the xylanase activity. The reaction system consisted of $100 \mu \mathrm{L}$ of appropriately diluted enzyme solution and $900 \mu \mathrm{L}$ of $1 \%(\mathrm{w} / \mathrm{v})$ xylan in Mcllvaine buffer $(\mathrm{pH}$ 6.0). The reaction mixture was incubated at $60{ }^{\circ} \mathrm{C}$ for $10 \mathrm{~min}$, then $1.5 \mathrm{~mL}$ of DNSA reagent was added to terminate the reaction. The mixture was boiled for exactly $5 \mathrm{~min}$ and cooled down to room temperature. The color formation was monitored at $540 \mathrm{~nm}$ and quantified by comparison with a standard curve of D-xylose. One unit of xylanase activity was defined as the amount of enzyme releasing $1 \mu \mathrm{M}$ of reducing sugars equivalent to D-xylose per minute under assay conditions. Each reaction was performed in triplicate, as was each experiment.

\section{Biochemical characterization}

The optimal $\mathrm{pH}$ for the Abf activity of purified recombinant Ac-Abf51A $(3 \mu \mathrm{g} / \mathrm{mL})$ was determined at $37{ }^{\circ} \mathrm{C}$

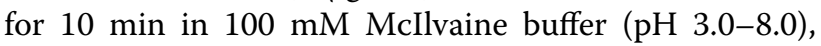
$100 \mathrm{mM}$ Tris- $\mathrm{HCl}(\mathrm{pH} 8.0-9.0)$ and $100 \mathrm{mM}$ glycine$\mathrm{NaOH}$ (pH 9.0-10.0). The stability of Ac-Abf51A under different $\mathrm{pH}$ conditions was assessed by measuring the residual activities under standard conditions after incubation of the enzyme $(60 \mu \mathrm{g} / \mathrm{mL})$ in the buffers as described above at $37{ }^{\circ} \mathrm{C}$ for $1 \mathrm{~h}$. The optimal temperature for Ac-Abf51A activity $(3 \mu \mathrm{g} / \mathrm{mL})$ was carried out at various temperatures from 20 to $80{ }^{\circ} \mathrm{C}$ in $100 \mathrm{mM}$ McIlvaine buffer ( $\mathrm{pH}$ 6.0). Thermal stability was determined by measuring the residual activities under standard conditions [100 mM Mcllvaine buffer (pH 6.0), $60{ }^{\circ} \mathrm{C}$ for $10 \mathrm{~min}$ ] after incubating the enzyme $(60 \mu \mathrm{g} / \mathrm{mL})$ at $60{ }^{\circ} \mathrm{C}, 65^{\circ} \mathrm{C}, 70{ }^{\circ} \mathrm{C}$, and $80^{\circ} \mathrm{C}$ for different times without substrate.

The Abf activity of Ac-Abf51A was also analyzed in the presence of $5 \mathrm{mM}$ of $\mathrm{NaCl}, \mathrm{KCl}, \mathrm{MgSO}_{4}, \mathrm{CaCl}_{2}, \mathrm{AgNO}_{3}$, $\mathrm{ZnSO}_{4}, \mathrm{FeCl}_{3}, \mathrm{NiSO}_{4}, \mathrm{CuSO}_{4}, \mathrm{MnSO}_{4}, \mathrm{CrCl}_{3}, \mathrm{CoCl}_{2}$, $\mathrm{Pb}\left(\mathrm{CH}_{3} \mathrm{COO}\right)_{2}$, SDS, EDTA, and $\beta$-mercaptoethanol. The system without any additive was used as control.

\section{Substrate specificity and kinetic parameters}

The Ac-Abf51A activities against different substrates were measured as described below. When using $1 \mathrm{mM}$ of 4-nitrophenyl-glycosides including 4-nitrophenyl- $\alpha$ L-arabinofuranoside, 4-nitrophenyl- $\beta$-D-xylopyranoside, 4-nitrophenyl- $\alpha$-D-galactopyranoside, 2 -nitrophenyl- $\beta$-Dgalactopyranoside, 4-nitrophenyl- $\alpha$-D-glucopyranoside, 
4-nitrophenyl- $\alpha$-L-arabinopyranoside, $p$-nitrophenyl-acetate, $\alpha-1,5$-linked arabinooligosaccharides (arabinobiose, arabinotriose, and arabinotetraose), and 4-nitrophenyl$\alpha$-D-glucuronide as the substrates (Sigma), the enzyme activities were determined at $\mathrm{pH} 6.0,60{ }^{\circ} \mathrm{C}$ for $10 \mathrm{~min}$. When using $1 \%(\mathrm{w} / \mathrm{v})$ polysaccharides, such as sugar beet arabinan, debranched sugar beet arabinan, red debranched arabinan (dyed with Procion Red dye specific for the endo-1,5-arabinanase activity; Megazyme), gum arabic, water-soluble wheat arabinoxylan) and xylooligosaccharides $(200 \mu \mathrm{g} / \mathrm{mL}$ of xylobiose, xylotriose, xylotetraose, xylopentaose, and xylohexaose; Megazyme) as the substrates, the enzyme activities were determined using high-performance anion exchange chromatography (HPAEC; Thermo Fisher Scientific) equipped with a Carbo-Pac PA200 column $(3 \mu \mathrm{m} \times 250 \mathrm{~mm})$. The reaction mixtures were incubated at $\mathrm{pH} 6.0,37{ }^{\circ} \mathrm{C}$ for $12 \mathrm{~h}$, followed by 10-min boiling water bath to terminate the reaction and centrifugation at $12,000 \times g$ for $5 \mathrm{~min}$ to remove unsolved residues. To remove the extra enzyme protein, the clear supernatants were centrifuged $\left(10,000 \times g, 4{ }^{\circ} \mathrm{C}, 10 \mathrm{~min}\right)$ through a $3-\mathrm{kDa}$ Amicon Ultra centrifugal filter (Millipore). The filtrates were diluted 100 -fold in $\mathrm{ddH}_{2} \mathrm{O}$, and $25 \mu \mathrm{l}$ of each sample was subject to HPAEC analysis. $\mathrm{NaOH}(100 \mathrm{mM})$ was used to elute the saccharides at the flow rate of $0.3 \mathrm{~mL} / \mathrm{min}$. Arabinose, xylose, xylobiose, xylotriose, xylotetraose, xylopentaose, and xylohexaose served as standards.

Enzyme kinetic assays were performed at $\mathrm{pH} 6.0,60^{\circ} \mathrm{C}$ for 5 min with 4-nitrophenyl- $\alpha$-L-arabinofuranoside (1-10 $\mathrm{mM}$ ) as the substrate. The $K_{\mathrm{m}}$ and $V_{\max }$ values of Ac-Abf51A were plotted based on Lineweaver-Burk method. The catalytic efficiency $\left(k_{\mathrm{cat}} / K_{\mathrm{m}}\right)$ of Ac-Abf51A towards xylooligosaccharides was determined following the Matsui equation as previously described by Cervera-Tison et al. [44].

\section{Mutant construction and characterization}

To further verify whether the $\alpha$-L-arabinofuranosidase and endo-xylanase activities of Ac-Abf51A were derived from the same module and the active center, truncation mutants of single module (Ac-Abf51An and Ac-Abf51Ac) and substitution mutants (Glu175 and Glu294) were performed using the Quik-Change method (Stratagene). All mutations were generated in the wild-type Ac-Abf51A DNA in the expression plasmid. The resulting mutant plasmids were transformed into E. coli BL21 (DE3) cells and confirmed by DNA sequencing. Expression, purification, and characterization of the mutant enzymes followed the same procedure as for the Ac-Abf51A.

\section{Synergetic effects of Ac-Abf51A and xylanase XynBE18}

Endo-xylanase XynBE18 from Paenibacillus sp. E18 [41, 45 ] is an excellent xylooligosaccharide producer and was selected for enzyme combination. The reaction mixtures were composed of $900 \mu \mathrm{L}$ of $0.5 \%(\mathrm{w} / \mathrm{v})$ water-soluble wheat arabinoxylan and $100 \mu \mathrm{l}$ of enzyme(s) $(0.5 \mathrm{U}$ each of XynBE18 and/or Ac-Abf51A). All reactions were carried out at $37{ }^{\circ} \mathrm{C}$ in $100 \mathrm{mM}$ Mcllvaine buffer (pH 6.0). After 12-h incubation, the reaction mixtures were immersed in boiling water for $10 \mathrm{~min}$ to stop the reactions. Blank controls containing substrate alone were treated under the same conditions. For the sequential reactions, the second enzyme solutions were added after heat denaturation. The hydrolysates were assessed using HPAEC as described above. The degree of synergy was defined as the ratio of reducing sugar equivalents released when enzymes were incubated simultaneously or sequentially to the sum of the reducing sugar equivalents released by each enzyme alone.

\section{Additional files}

Additional file 1: The three-dimensional structure model of Ac-Abf51A, E175 and E294 are putative catalytic residues.

Additional file 2: HPAEC analyses of the hydrolysis products of sugar beet arabinan (A) and debranched sugar beet arabinan (B). 1, the arabinose and xylooligosaccharide standards: Ara, arabinose; $X 1, x y l o s e ;$ X2, xylobiose; X3, xylotriose; X4, xylotetraose; X5, xylopentaose; and X6, xylohexaose. 2 , the control of substrate incubated without enzyme for $12 \mathrm{~h} ; 3$, the substrate hydrolysates by Ac-Abf51A treatment at $\mathrm{pH} 6.0$ and $37^{\circ} \mathrm{C}$ for $12 \mathrm{~h}$

Additional file 3: HPAEC analyses of the hydrolysis products of xylooligosaccharides. (A) Xylotetraose. (B) Xylopentaose. (C) Xylohexaose. 1, the xylooligosaccharide substrates; 2 , the xylooligosaccharide hydrolysates by $\mathrm{Ac}-\mathrm{Abf} 51 \mathrm{~A}$ treatment at $\mathrm{pH} 6.0$ and $37^{\circ} \mathrm{C}$ for $12 \mathrm{~h}$; 3 , the xylooligosaccharide standards.

\section{Abbreviations}

GH: glycosyl hydrolase; Abfs: a-L-arabinofuranosidases; LB: Luria-Bertani; IPTG isopropyl- $\beta$-D-1-thiogalactopyranoside; Ac-Abf51A: a-L-arabinofuranosidase from Alicyclobacillus sp. A4; $K_{m}$ : Michaelis constant; $V_{\text {max }}$ : maximum reaction rate; $k_{\text {cat }}$ : turnover number; DNSA: 3,5-dinitrosalicylic acid; HPAEC: high-performance anion exchange chromatography; PDB: protein database.

\section{Authors' contributions}

$W Y$ and $Y B$ designed the study, performed the major experiments containing the enzyme production and substrate specificity assay, and wrote the manuscript. PY, HL, and HH performed HPAEC analysis. KM and YW participated in the discussion and revised the manuscript. PS and BY were the corresponding authors; they supervised the work and the writing of the manuscript. All authors read and approved the final manuscript.

\section{Acknowledgements}

This research was supported by the National High Technology Research and Development Program of China (2013AA102803), the National Science Foundation for Distinguished Young Scholars of China (31225026), the National Natural Science Foundation of China (31101346), and the China Modern Agriculture Research System (CARS-42).

\section{Competing interests}

The authors declare that they have no competing interests.

Received: 3 December 2014 Accepted: 27 October 2015 Published online: 30 November 2015 


\section{References}

1. Saha BC. Hemicellulose bioconversion. J Ind Microbiol Biotechnol. 2003;30:279-91.

2. Scheller HV, Ulvskov P. Hemicelluloses. Annu Rev Plant Biol. 2010;61:263-89.

3. Gírio FM, Fonseca C, Carvalheiro F, Duarte LC, Marques S, BogelŁukasik R. Hemicelluloses for fuel ethanol: a review. Bioresour Technol. 2010;101:4775-800

4. Pauly M, Gille S, Liu L, Mansoori N, de Souza A, Schultink A, Xiong G. Hemicellulose biosynthesis. Planta. 2013;238:627-42.

5. Song L, Siguier B, Dumon C, Bozonnet S, O'Donohue MJ. Engineering better biomass-degrading ability into a GH11 xylanase using a directed evolution strategy. Biotechnol Biofuels. 2012;5:3.

6. Bastawde KB. Xylan structure, microbial xylanases, and their mode of action. World J Microbiol Biotechnol. 1992;8:353-68.

7. Sunna A, Antranikian G. Xylanolytic enzymes from fungi and bacteria. Crit Rev Biotechnol. 1997;17:39-67.

8. Numan MT, Bhosle NB. a-L-Arabinofuranosidases: the potential applications in biotechnology. J Ind Microbiol Biotechnol. 2006;33:247-60.

9. Gao D, Uppugundla N, Chundawat SP, Yu X, Hermanson S, Gowda K, Brumm P, Mead D, Balan V, Dale BE. Hemicellulases and auxiliary enzymes for improved conversion of lignocellulosic biomass to monosaccharides. Biotechnol Biofuels. 2011:4:5.

10. Beylot MH, Emami K, McKie VA, Gilbert HJ, Pell G. Pseudomonas cellulosa expresses a single membrane-bound glycoside hydrolase family 51 arabinofuranosidase. Biochem J. 2001;358:599-605.

11. van Laere KM, Hartemink R, Bosveld M, Schols HA, Voragen AG. Fermentation of plant cell wall derived polysaccharides and their corresponding oligosaccharides by intestinal bacteria. J Agric Food Chem. 2000;48:1644-52.

12. Spagna G, Romagnoli D, Angela M, Bianchi G, Pifferi PG. A simple method for purifying glycosidases: $\mathrm{Q}$-L-arabinofuranosidase and $\beta$-Dglucopyranosidase from Aspergillus niger to increase the aroma of wine, Part I. Enzyme Microb Tech. 1998;22:298-304.

13. Aristidou A, Penttilä M. Metabolic engineering applications to renewable resource utilization. Curr Opin Biotechnol. 2000;11:187-98.

14. Henrissat B, Davies GJ. Glycoside hydrolases and glycosyltransferases. Families, modules, and implications for genomics. Plant Physiol. 2000;124:1515-9.

15. Fritz M, Ravanal MC, Braet C, Eyzaguirre J. A family $51 \mathrm{a}-\mathrm{L}-$ arabinofuranosidase from Penicillium purpurogenum: purification, properties and amino acid sequence. Mycol Res. 2008;112:933-42.

16. Taylor EJ, Smith NL, Turkenburg JP, D'Souza S, Gilbert HJ, Davies GJ. Structural insight into the ligand specificity of a thermostable family 51 arabinofuranosidase, Araf51, from Clostridium thermocellum. Biochem J. 2006;395:31-7.

17. Canakci S, Kacagan M, Inan K, Belduz AO, Saha BC. Cloning, purification, and characterization of a thermostable $a$-L-arabinofuranosidase from Anoxybacillus kestanbolensis AC26Sari. Appl Microbiol Biotechnol. 2008;81:61-8.

18. Schwarz WH, Bronnenmeier K, Krause B, Lottspeich F, Staudenbauer WL. Debranching of arabinoxylan: properties of the thermoactive recombinant a-L-arabinofuranosidase from Clostridium stercorarium (ArfB). Appl Microbiol Biotechnol. 1995;43:856-60.

19. Shallom D, Belakhov V, Solomon D, Gilead-Gropper S, Baasov T, Shoham G, Shoham Y. The identification of the acid-base catalyst of a-arabinofuranosidase from Geobacillus stearothermophilus T-6, a family 51 glycoside hydrolase. FEBS Lett. 2002;514:163-7.

20. Degrassi G, Vindigni A, Venturi V. A thermostable a-arabinofuranosidase from xylanolytic Bacillus pumilus: purification and characterisation. J Biotechnol. 2003;101:69-79.

21. Margolles A, de los Reyes-Gavilán CG. Purification and functional characterization of a novel a-L-arabinofuranosidase from Bifidobacterium longum B667. Appl Environ Microbiol. 2003;69:5096-103.

22. Manin C, Shareek F, Morosoli R, Kluepfel D. Purification and characterization of an $a-\mathrm{L}$-arabinofuranosidase from Streptomyces lividans 66 and DNA sequence of the gene (abfA). Biochem J. 1994;302:443-9.

23. Tajana E, Fiechter A, Zimmermann W. Purification and characterization of two a-L-arabinofuranosidases from Streptomyces diastaticus. Appl Environ Microbiol. 1992;58:1447-50.
24. Tsujibo H, Takada C, Wakamatsu Y, Kosaka M, Tsuji A, Miyamoto K, Inamori Y. Cloning and expression of an a-L-arabinofuranosidase gene (stx/V) from Streptomyces thermoviolaceus OPC-520, and characterization of the enzyme. Biosci Biotechnol Biochem. 2002;66:434-8.

25. Arab-Jaziri F, Bissaro B, Barbe S, Saurel O, Débat H, Dumon C, Gervais V, Milon A, André I, Fauré R, O'Donohue MJ. Functional roles of H98 and W99 and $\beta 2$ a2 loop dynamics in the $\alpha$ - $L$-arabinofuranosidase from Thermobacillus xylanilyticus. FEBS J. 2012;279:3598-611.

26. Saha BC. a-L-Arabinofuranosidases biochemistry, molecular biology and application in biotechnology. Biotechnol Adv. 2000;18:403-23.

27. Chang SS, Kang DH. Alicyclobacillus spp. in the fruit juice industry: history, characteristics, and current isolation/detection procedures. Crit Rev Microbiol. 2004;30:55-74.

28. Eckert K, Zielinski F, Lo Leggio L, Schneider E. Gene cloning, sequencing, and characterization of a family 9 endoglucanase (CelA) with an unusual pattern of activity from the thermoacidophile Alicyclobacillus acidocaldarius ATCC27009. Appl Microbiol Biotechnol. 2002;60:428-36.

29. Bai Y, Wang J, Zhang Z, Shi P, Luo H, Huang H, Feng Y, Yao B. Extremely acidic $\beta$-1,4-glucanase, CelA4, from thermoacidophilic Alicyclobacillus sp. A4 with high protease resistance and potential as a pig feed additive. J Agric Food Chem. 2010;58:1970-5.

30. Eckert K, Schneider E. A thermoacidophilic endoglucanase (CelB) from Alicyclobacillus acidocaldarius displays high sequence similarity to arabinofuranosidases belonging to family 51 of glycoside hydrolases. Eur J Biochem. 2003;270:3593-602.

31. Bai Y, Wang J, Zhang Z, Yang P, Shi P, Luo H, Meng K, Huang H, Yao B. A new xylanase from thermoacidophilic Alicyclobacillus sp. A4 with broad-range $\mathrm{pH}$ activity and $\mathrm{pH}$ stability. J Ind Microbiol Biotechnol. 2010;37:187-94.

32. Zhang S, Wang H, Shi P, Xu B, Bai Y, Luo H, Yao B. Cloning, expression, and characterization of a thermostable $\beta$-xylosidase from thermoacidophilic Alicyclobacillus sp. A4. Process Biochem. 2014;49:1422-8.

33. Zhang Y, Ju J, Peng H, Gao F, Zhou C, Zeng Y, Xue Y, Li Y, Henrissat B, Gao G, Ma Y. Biochemical and structural characterization of the intracellular mannanase AaManA of Alicyclobacillus acidocaldarius reveals a novel glycoside hydrolase family belonging to clan GH-A.J Biol Chem. 2008;283:31551-8.

34. Hövel K, Shallom D, Niefind K, Belakhov V, Shoham G, Baasov T, Shoham Y, Schomburg D. Crystal structure and snapshots along the reaction pathway of a family 51 a-L-arabinofuranosidase. EMBO J. 2003;22:4922-32.

35. Canakci S, Belduz AO, Saha BC, Yasar A, Ayaz FA, Yayli N. Purification and characterization of a highly thermostable a-L-arabinofuranosidase from Geobacillus caldoxylolyticus TK4. Appl Microbiol Biotechnol. 2007;75:813-20.

36. Gilead S, Shoham Y. Purification and characterization of a-Larabinofuranosidase from Bacillus stearothermophilus T-6. Appl Environ Microbiol. 1995;61:170-4.

37. Matsuo N, Kaneko S, Kuno A, Kobayashi H, Kusakabe I. Purification, characterization and gene cloning of two a-L-arabinofuranosidases from Streptomyces chartreusis GS901. Biochem J. 2000;346:9-15.

38. Beylot MH, McKie VA, Voragen AG, Doeswijk-Voragen CH, Gilbert HJ. The Pseudomonas cellulosa glycoside hydrolase family 51 arabinofuranosidase exhibits wide substrats specificity. Biochem J. 2001;358:607-14.

39. Ji L, Yang JS, Fan H, Yang Y, Li BZ, Yu XJ, Zhu N, Yuan HL. Synergy of crude enzyme cocktail from cold-adapted Cladosporium cladosporioides Ch2-2 with commercial xylanase achieving high sugars yield at low cost. Biotechnol Biofuels. 2014;7:130.

40. $\mathrm{Hu}$ J, Arantes V, Saddler JN. The enhancement of enzymatic hydrolysis of lignocellulosic substrates by the addition of accessory enzymes such as xylanase: is it an additive or synergistic effect? Biotechnol Biofuels. 2011;4:1-14.

41. Shi P, Chen X, Meng K, Huang H, Bai Y, Luo H, Yang P, Yao B. Distinct actions by Paenibacillus sp. strain E18 a-L-arabinofuranosidases and xylanase in xylan degradation. Appl Environ Microbiol. 2013;79:1990-5.

42. Shi P, Li N, Yang P, Wang Y, Luo H, Bai Y, Yao B. Gene cloning, expression, and characterization of a family $51 \mathrm{a}-\mathrm{L}$-arabinofuranosidase from Streptomyces sp. S9. Appl Biochem Biotechnol. 2010;162:707-18.

43. Miller GL. Use of dinitrosalicylic acid reagent for determination of reducing sugar. Anal Chem. 1959;31:426-8. 
44. Cervera Tison M, André-Leroux G, Lafond M, Georis J, Juge N, Berrin JG. Molecular determinants of substrate and inhibitor specificities of the Penicillium griseofulvum family 11 xylanases. Biochim Biophys Acta 2009:1794:438-45.
45. Shi P, Tian J, Yuan T, Liu X, Huang H, Bai Y, Yang P, Chen X, Wu N, Yao B. Paenibacillus sp. strain E18 bifunctional xylanase-glucanase with a single catalytic domain. Appl Environ Microbiol. 2010;76:3620-4.

Submit your next manuscript to BioMed Central and take full advantage of:

- Convenient online submission

- Thorough peer review

- No space constraints or color figure charges

- Immediate publication on acceptance

- Inclusion in PubMed, CAS, Scopus and Google Scholar

- Research which is freely available for redistribution

Submit your manuscript at

www.biomedcentral.com/submit

() BioMed Central 